\title{
Human disturbance and conspecifics influence display site selection by Great Bustards Otis tarda
}

\author{
ROBERT J. BURNSIDE, ZSOLT VÉGVÁRI, RICHARD JAMES, \\ SANDOR KONYHÁS, GÁBOR KOVÁCS and TAMÁS SZÉKELY
}

\begin{abstract}
Summary
Understanding habitat selection and assessing habitat quality have an important role in habitat management and prioritisation of areas for protection. However, interpretations of habitat selection and habitat quality can be confounded by social effects such as conspecific attraction. Using 7 years' data from a well monitored Great Bustard Otis tarda population in Central Europe, we investigated the roles of human disturbance and social cues in display site selection of male Great Bustards Otis tarda. The spatial distribution of displaying males was best predicted by human disturbance. In addition, the number of males attending display sites was strongly correlated to the number of females present and not with disturbance. This suggests that abundance could be a misleading metric for habitat quality in social species. Our results highlight the roles of disturbance and social cues in male habitat choice, and suggest that social factors need to be taken into consideration for management of endangered populations.
\end{abstract}

\section{Introduction}

Understanding habitat selection and assessing habitat quality have underpinned in situ species conservation planning (Jones 2001, Morris 2003). It allows conservation managers to make decisions about how to manage habitats and prioritise areas for protection (Root-Bernstein and Ladle 2010). It is based on the assumptions that site selection is non-random, and that individuals assess information from multiple cues to make an optimal decision about which habitat to occupy (Jones 2001, Morris 2003, Johnson 2007). An animal's habitat choice can have important fitness consequences. In particular, breeding site choice and quality influence an individual's reproductive success (Doligez et al. 2002). Therefore, understanding the factors that influence habitat selection and habitat quality are important for managing habitats for endangered species. Investigating habitat selection has primarily been based on the correlation of biotic and abiotic variables with occupancy while habitat quality has been correlated with the number of individuals attending a site (Vanhorne 1983, Morris 2003).

Conspecific attraction can confound traditional interpretations of habitat selection as it violates the assumption that each individual independently assesses a site (Vanhorne 1983, Skagen and Adams 2011). Rather than sampling a location by trial and error, an individual may use the presence of conspecifics as indicators of habitat quality, thereby reducing searching costs (Muller et al. 1997). In some species, the attraction to choose a site with conspecifics present may be cumulative and could lead to additive aggregation. Social attraction in habitat choice may explain why some species are more sensitive to habitat fragmentation and slow to recolonise empty habitats (Fletcher 2007). Therefore, understanding the roles of social behaviour in habitat selection can give important insights into improving the conservation biology of social species (Ahlering et al. 2010). 
The Great Bustard Otis tarda is a globally threatened species (IUCN category "Vulnerable"). During the $19^{\text {th }}$ and $20^{\text {th }}$ centuries, the European populations of the species had rapidly declined. Multiple national and local extinctions have left current populations small and highly fragmented (Palacin and Alonso 2008). The Great Bustard has suffered habitat loss due to increasing nonlethal human disturbance (Lane et al. 2001, Suarez-Seoane et al. 2002, Sastre et al. 2009, Burnside et al. 2012). The negative impacts of human disturbance on many threatened species is being increasingly recognised (Gill et al. 2001, Frid and Dill 2002).

Effective conservation of this species requires not only an understanding of its habitat requirements, but also how social attraction influences habitat selection. Great Bustards have a breeding system which can be described on a continuum between a classical lek and exploded lek as it does not fit either definition exactly (Morales et al. 2001). However, males gather in loose congregations and display to females. Males are not territorial and display at different sites within larger areas where display sites are concentrated. These areas contain resources for both males and females with females nesting in and around the lekking areas (Morales and Martin 2003). Habitat modelling and direct observations have found that many areas that are deemed suitable for breeding remain unoccupied and that new leks are rarely established (Osborne et al. 2001, Suarez-Seoane et al. 2002, Alonso et al. 2004). Conspecific attraction has been suggested as the mechanism for the presence of unutilised habitat, and this has been corroborated by dispersal studies (Martin et al. 2008).

Here we use generalised linear models to investigate display site selection and attendance of Great Bustards from a small and well monitored population in Hungary. Our aims were to establish the roles of social influences and human disturbance on male display site choice. To achieve these aims we tested two hypotheses: 1 ) display site selection: are display site locations different from random areas within the greater national park in relation to human disturbance and vegetation structure? and 2) display site attendance: do females influence the number of males at display sites?

\section{Methods}

\section{Study Area}

Hortobágy National Park (henceforth HNP- Figure 1) is a large, unbroken alkaline grassland in Europe, consisting of steppe interspersed with alkaline marshes (Ecsedi 2004). It is located in eastern Hungary $\left(47^{\circ} 3 \mathrm{O}^{\prime} \mathrm{N} 21^{\circ} \mathrm{O}^{\prime} \mathrm{E}\right.$, Figure $\left.\mathrm{I}\right)$, and has a Great Bustard population estimated at 140 individuals (Ecsedi 2004). It is managed through grazing of various livestock, including domestic cattle Bos taurus and sheep Ovis aries.

\section{Survey methodology}

Male Great Bustards perform conspicuous mating displays each spring. The displays are usually performed by congregations of males competing at a display site. Surveys were carried out to locate displaying males in HNP. At each observation, the number of males and females present and the centre of the group location were recorded. Any observation with $\geq 3$ males present was defined as a display site. Surveys were carried out between 2000 and 2007 during the breeding seasons (March to May). Data from 2004 were excluded due to poor quality satellite images (see below), but were available for model validation after the habitat selection analysis.

Surveys covered the whole national park, and all areas were visited approximately every four days in a standardised manner. Searches occurred during peak display times in the morning (o6hoo-09hoo, CET) and evening (16hoo-19hoo, CET). During each survey, approximately 10o $\mathrm{km}$ were covered using four-wheel drive vehicles, bicycles or walking. Surveys involved stopping at observation points and searching with binoculars and telescopes. The male population is estimated to be 50-70 individuals, all of which can be located during the lekking season. Surveys were 


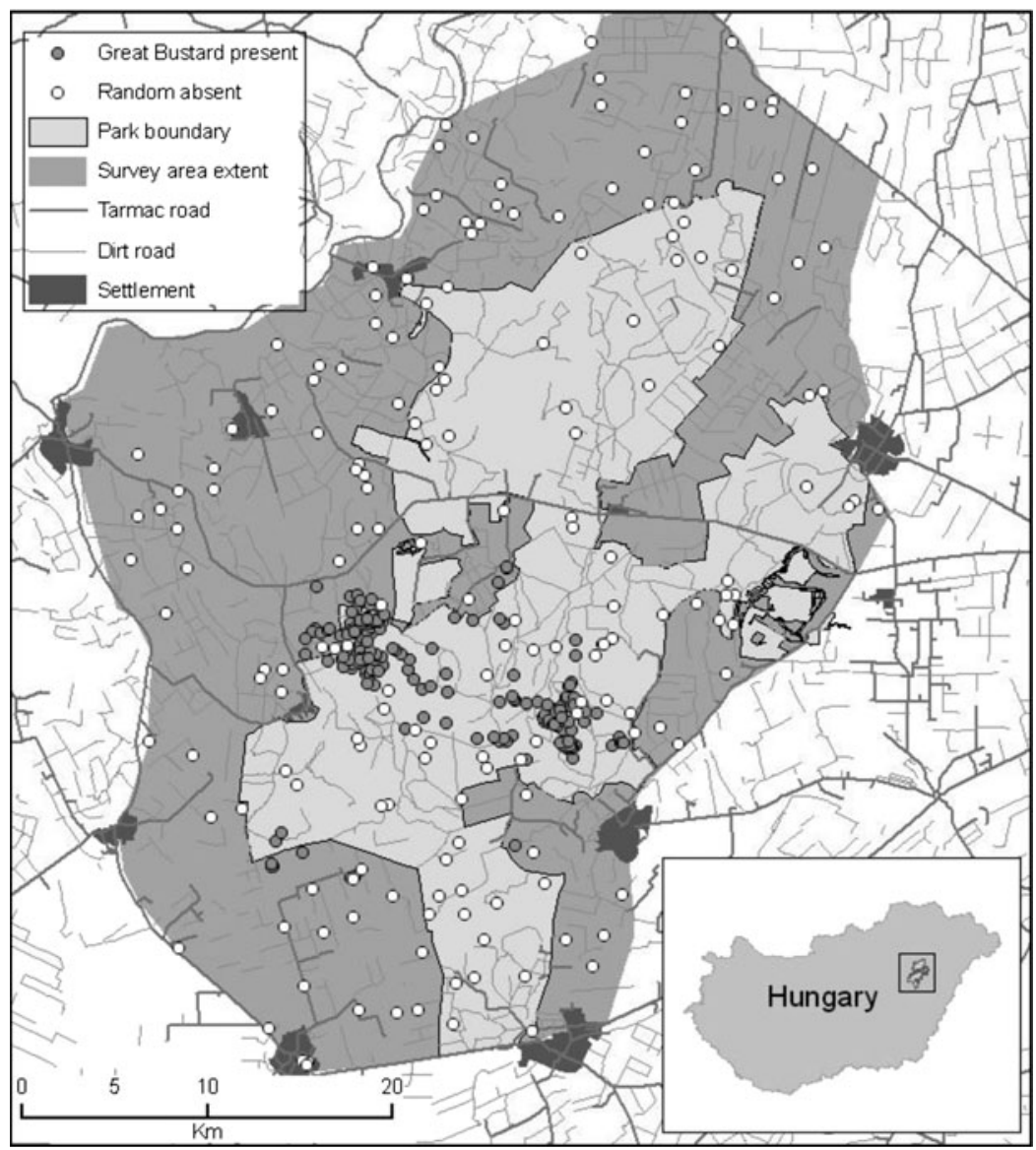

Figure 1. Location of Great Bustard display sites in Hortobágy National Park, Hungary and in the surrounding area. Surveys were carried out both within the National Park, and the grey shaded area outside.

made by three observers with several years of fieldwork experience; they are permanently employed to monitor and manage the HNP Great Bustard population (ZV, SK and GK). All observations were plotted in the UTM $34 \mathrm{~N}$ reference system using the WGS 1984 datum. Random habitat data were generated from random points within the boundary of the sampling area of HNP (Figure I). We used an equal number of random points as display site points, and constrained the random points by excluding water bodies such as streams, ponds and marshes.

\section{Disturbance and habitat variables}

HNP is mainly managed through traditional grazing practices that produce a different intensity of grazed grassland. In addition, it is open to visitors with several dirt tracks and single lane tarmac roads for travel (Figure 1 ): there is only one two-lane tarmac road dissecting the national park. These roads are potential sources of disturbance. Therefore our a priori hypothesis was that disturbance by humans, and vegetation characteristics influence the spatial distribution of display sites. We identified eight disturbance and remotely sensed variables (Table 1 ) based on this information. All variables, except dirt road density, were quantified at a $30-\mathrm{m}$ resolution whereas the 
Table 1 . Variables representing human disturbance and vegetation structure were obtained via remote sensing (mean values \pm standard error for presence sites, $n=160$, and randomly chosen sites, $n=160$ ). The difference between means was not statistically tested due to spatial autocorrelation in display sites.

\begin{tabular}{|c|c|c|c|}
\hline Habitat variable & Description & Display sites & Random \\
\hline Dirt road density $\left(\mathrm{m} / \mathrm{km}^{2}\right)$ & $\begin{array}{l}\text { The total distance in metres covered } \\
\text { by dirt roads within a } 1-\mathrm{km} \text { square } \\
\text { was used as a metric for road density }\end{array}$ & $723.2 \pm 55.8$ & $821.8 \pm 53.2$ \\
\hline Distance to road (m) & $\begin{array}{l}\text { Distance from observation, in metres, } \\
\text { to nearest tarmac road. Calculated } \\
\text { at a } 30 \mathrm{~m} \text { resolution }\end{array}$ & $3001.5 \pm 66.4$ & $2075 \cdot 3 \pm 118.2$ \\
\hline Distance to settlement (m) & $\begin{array}{l}\text { Distance from observation, in metres, } \\
\text { to nearest settlement, human } \\
\text { population. Calculated at a } 30 \mathrm{~m} \\
\text { resolution }\end{array}$ & $5223.2 \pm 112.7$ & $5781.2 \pm 229.2$ \\
\hline Distance to sheep (m) & $\begin{array}{l}\text { Distance from observation, in metres, } \\
\text { to nearest area grazed by sheep. } \\
\text { Calculated at a } 30 \mathrm{~m} \text { resolution }\end{array}$ & $1529.4 \pm 77.6$ & $2491.3 \pm 152.5$ \\
\hline Distance to cattle (m) & $\begin{array}{l}\text { Distance from observation, in metres, } \\
\text { to nearest area grazed by cattle. } \\
\text { Calculated at a } 30 \mathrm{~m} \text { resolution }\end{array}$ & $1428.0 \pm 64.8$ & $2642.4 \pm 160.2$ \\
\hline TasCap brightness & $\begin{array}{l}\text { Tasselled cap brightness } \\
\text { (soil reflectance). } 30 \mathrm{~m} \text { resolution }\end{array}$ & $116.8 \pm 1.5$ & $114.8 \pm 1.5$ \\
\hline TasCap wetness & $\begin{array}{l}\text { Tasselled cap wetness value } \\
\text { (soil moisture). } 30 \mathrm{~m} \text { resolution }\end{array}$ & $-48.9 \pm 1.7$ & $-46.3 \pm 1.7$ \\
\hline TasCap greenness & $\begin{array}{l}\text { Tasselled cap greenness value } \\
\text { (chlorophyll content). } 30 \mathrm{~m} \\
\text { resolution }\end{array}$ & $0.05 \pm 0.01$ & $0.05 \pm 0.01$ \\
\hline
\end{tabular}

latter was quantified at $1-\mathrm{km}$ resolution. These scales were considered fine enough to capture variation in the variables that would be meaningful for Great Bustards. Differences between presences and random means could not be preliminarily tested due to spatial autocorrelation in the presence data. Data for tarmac and dirt roads were obtained from existing shapefiles from HNP.

To estimate the impact of human disturbance, every farm within the study area was mapped and the number of livestock kept each year taken from the HNP's livestock register. Herdsmen keep their livestock at their farms in winter and in spring move the herds outdoors where they spend the summer. This involves moving the animals to new grazing areas outside the farm each day. HNP management estimates that an area of $I$ ha is needed to graze either $I$ cattle or 10 sheep during spring (Z. Végvári in litt. 2010). The total area required for livestock was calculated for each farm. A circular buffer of equivalent size was drawn around the farm which represented the area of disturbance from livestock. Observations within the grazed area were classified as o $\mathrm{m}$ from the disturbed area. All Euclidean distances were calculated using ArcView v 9.I and dirt road density was calculated using Hawth's Tools (Beyer 2004).

To test the influence of vegetation, we chose to use remotely sensed variables. The tasselled cap transformation provides three orthogonal vegetation indexes that are calculated from six bands of Landsat 7 enhanced thematic mapper plus (ETM+) data (Kauth and Thomas 1976, Crist and Cicone 1984), using coefficients for the Landsat ETM+ sensor to reduce reflectance and extract biological data (Huang et al. 1998). We produced three raster images for each year; tasselled cap moisture describes the surface water present, tasselled cap brightness describes the soil characteristics (i.e. bare earth present) and tasselled cap greenness describes the amount of green vegetation present. We chose Landsat 7 ETM+ multispectral satellite data because of its fine scale high resolution images $(30 \mathrm{~m})$ and images were readily available for the study area. We used 11 scenes acquired from March, April or May from 2000 to 2007 (tile IDs are listed in Table SI in the 
online Supplementary Material). Images which had the best coverage and least cloud cover were selected. Landsat 7 images acquired after 2004 are vulnerable to Scan Line Corrector failure-OFF gaps, leaving data gaps in the image. Therefore scenes from 2004 to 2007 required multiple images that were temporally close and free of cloud cover, to fill data gaps. Sufficient data were not available for 2004 to create a satisfactory mosaic and were consequently excluded from the analysis. Satellite images were downloaded from United States Geographical Service (http://www.usgs.gov). Atmospheric correction was carried out on bands $1,2,3,4,5$ and 7 and images were then clipped to the extent of the study area (Figure 1 ), covering a total area of $3,696 \mathrm{~km}^{2}$. All image processing was done in Idrisi Kilimanjaro (Eastman 2003).

\section{Statistical analysis}

We used generalised linear models (GLMs), and model simplification to identify variables that influence bustard distribution. A maximal model was fitted with all explanatory variables and simplified by stepwise deletion of non-significant terms. Each deletion was tested for a significant increase in deviance by ANOVA. This was repeated until the minimum adequate model (MAM) contained only significant terms (Crawley 2007). Finally, ANOVA was used to test if there was a significant increase in deviance between the maximal model and the MAM. Although there is some debate between the use of stepwise simplification and information theory for best model selection, both have received criticism for their misuse (Bolker et al. 2008, Burnham and Anderson 2002, Mundry 2011). Here we chose to use stepwise deletion rather than an information theoretic approach because it retains variables only if they significantly explain variation in the response variable. The objective of our parsimonious approach was to use the variables that contribute significantly in habitat selection to further model site attendance. Information theory and model averaging would likely lead to the inclusion of non-significant variables. We modelled the probability of Great Bustard presence against random points within the study buffer area (Figure I) using binary logistic regression with binomial errors.

Count and distance explanatory variables were normalised and rescaled by square-root and $\log _{e}(x+1)$ transformations to improve the fit of models to the data, respectively (Crawley 2007). All pairs of explanatory variables were screened for collinearity. There were no strong correlations $(r>0.5)$ between any of the explanatory variables allowing inclusion of all explanatory variables in the multiple regressions (Freckleton 2002).

To control for spatial autocorrelation in the response variables, often found in spatially aggregated lekking species (Gray et al. 2007), we added a spatially-weighted autologistic term described in Augustin et al. (1996) to all models following implementation and assessment of Gray et al. (2007). The term is a distance weighted sum of the numbers of observation points in squares surrounding the focal observation point and is calculated as follows:

$$
\text { autologistic term }=\sum_{j=1}^{k i} \frac{y_{j}}{h_{j i}}
$$

where $i$ is the survey point, $h_{i j}$ is the Euclidean distance between the surveyed point and the centre of the square $j, k$ is the lag distance from $i$ and $y j$ is the presence or absence of a survey point within the lag distance $k$.

The optimal lag distance $k$ was estimated by calculating the autologistic term for o $\mathrm{m}$ to 2,000 $\mathrm{m}$ in steps of $250 \mathrm{~m}$. Each estimate was then added to the maximum model and the $k$ value that produced the greatest reduction in deviance was chosen for model simplification. The greatest reduction was found for $k=1,000 \mathrm{~m}$. We used Moran's I to test for spatial autocorrelation within the residuals of the MAMs (Osborne et al. 2001).

To assess the fit of the model to the data and to validate its predictive power, we calculated area under the curve (AUC) for two separate Receiver Operating Characteristic plots (ROC). This compares the number of correctly predicted versus falsely predicted points from a set of independent data. An AUC value of $50 \%$ indicates that the model is predicting no better than random 
while 100\% means it is predicted all the points correctly (Osborne et al. 2001). We used the previously excluded 2004 data points to validate the predictive power of the model for independent data. All statistics were carried out in Program R v. 2.I2.I (R Development Core Team 2011).

\section{Site attendance model}

To investigate the influences of habitat quality and conspecifics on the number of male Great Bustards at a display site, we used counts from all presence points. After finding the MAM for the habitat selection model, we used the remaining significant variables to construct a model which also included the number of females observed at the observation. We further examined the influence of Julian date on male abundance and added an interaction term for date and female numbers. Female numbers are likely to decrease with time as females begin to nest. Following the same procedure as above, a spatial autocorrelation weighting was calculated for the presence only points. The optimal lag distance was found to be 3,00o m. Initially, Poisson errors were used, however, the residuals and variance were not normal and constant, respectively. Therefore we square-root transformed the response and used Gaussian errors which resulted in normal errors and constant variance.

\section{Results}

\section{Surveys}

There were a total of 160 observations holding three (or more) male Great Bustards. The mean number of mature males at a display site per observation was 9.5 \pm 0.4 males (SE unless stated otherwise, range $3-29$ ), and the mean number of females at a display site was $7.9 \pm 0.7$ females (range $0-36$ ). The largest mixed sex group was 56 , an estimated $40 \%$ of the HNP's population in a single gathering.

The display sites were non-randomly distributed within the national park (nearest neighbour: mean observed $=165.9 \mathrm{~m}$, mean expected $=1,050.9 \mathrm{~m}, z=-31.3, P<0.01$ ), and mainly found in the southern part of HNP (Figure 1). Kernel density estimation with $95 \%$ probability of occurrence, estimated that two lekking concentrations exist in the southern part of the park, covering $67 \mathrm{~km}^{2}$ and $79 \mathrm{~km}^{2}$. The centres of the lekking regions were separated by $11 \mathrm{~km}$. They covered a total of $8 \%$ of the surveyed area (study buffer). As there was spatial autocorrelation present in the display sites, we could not use traditional bivariate tests of difference in means. Table 1 describes the data for habitat variables.

\section{Habitat selection}

The MAM for habitat selection had two disturbance variables that significantly explained the probability of male Great Bustard occurrence (Table 2). The model indicated that bustards avoided human disturbance. Bustards were more likely to occur far from tarmac roads and areas with fewer dirt roads. There was no significant difference in the explanatory power of the maximal model and the MAM (ANOVA: $\mathrm{df}=6, F=1.48, P>0.05$ ). The residuals from the MAM displayed no spatial autocorrelation (Moran's I, $z=-0.25, P>0.05$ ).

The ROC indicated that the MAM fits the data well and explained $96.9 \%$ of the area under the curve (Figure 2a). Independent validation with survey data from 2004 showed that the predictive power was good, correctly predicting $80.7 \%$ of the presence and absence data (Figure $2 \mathrm{~b}$ ). There was no significant effect of disturbance from grazing, or from the remotely sensed variables such as tasselled cap wetness, greenness and brightness (Table 2).

\section{Number of males}

Distance from roads and dirt road density were included in the maximal model. After simplification, the MAM indicated that there was a strong positive correlation between the number of 
Table 2. Habitat selection model of male Great Bustard Otis tarda display sites using presence vs random sites ( $n=160$ observations). Minimum adequate generalised linear model with binomial errors and controlling spatial autocorrelation with autologistic term. See Table 1 for explanation of variables.

\begin{tabular}{llcc}
\hline Retained Variables & Beta & SE & $Z$ \\
\hline Intercept & -5.83 & 2.18 & $-2.67^{* *}$ \\
Distance to road (m) & 0.56 & 0.28 & $1.99^{*}$ \\
Dirt road density (m/km2) & -0.14 & 0.06 & $-2.27^{*}$ \\
Auto logistic term & 14.89 & 2.25 & $6.63^{* *}$ \\
MAM deviance & & & 166.85 \\
\hline Removed Variables & Order of removal & $\Delta$ Deviance $^{\dagger}$ \\
\hline Distance to cattle (m) & 6 & & 3.42 \\
Distance to sheep (m) & 5 & & 4.00 \\
Distance to settlement (m) & 4 & & 0.48 \\
TasCap wetness & 3 & & 0.35 \\
TasCap brightness & 2 & & 0.19 \\
TasCap greenness & 1 & 158.00 \\
Maximal model deviance & & & 0.41 \\
\hline
\end{tabular}

${ }^{+}$The change in deviance caused by the removal of the variable from the preceding model. Significances indicated as: $P<0.05^{*} ; P<0_{0.01 *}^{* *} P<0^{0.001^{* *}}$.

males and the number of females indicating the importance of social effects on display site attendance (Table 2, Figure 3). Disturbance and habitat features within the male display sites had no significant effect on the number of mature males attending (Table 2) and there was no significant loss of explanatory power by maximal model vs. MAM (ANOVA, $\mathrm{df}=4, F=0.44, P=0.78$ ). There was no spatial autocorrelation in the residuals of the MAM, (Moran's I, $z=0.64, P>0.05$ ).

\section{Discussion}

Differentiating between presence and attendance can give important insights into the mechanisms of habitat selection. We provide models of Great Bustard habitat preference and we examine the role

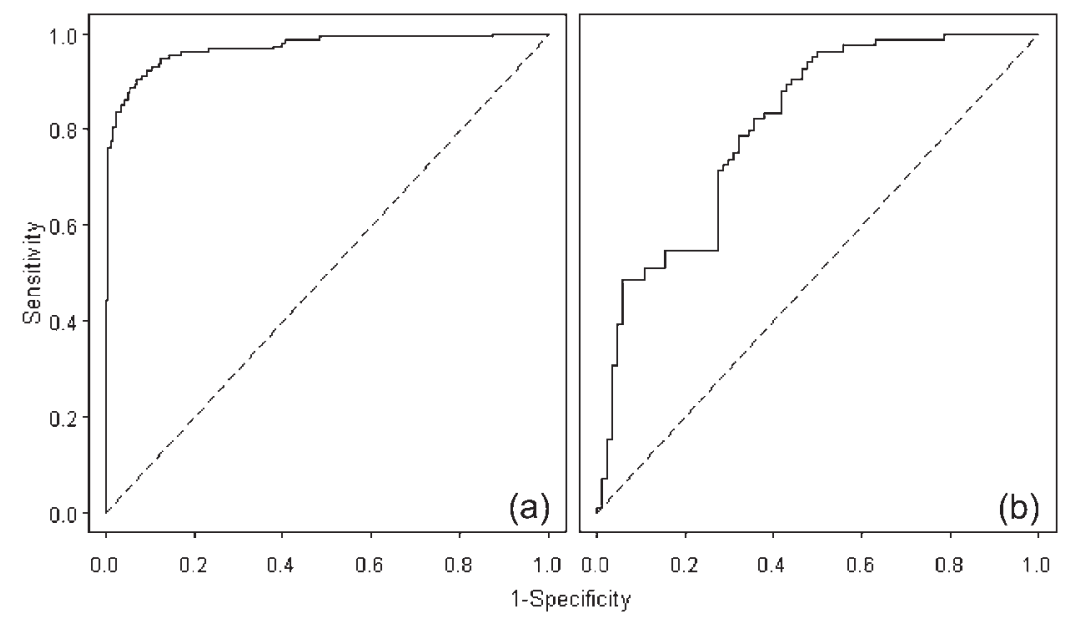

Figure 2. Receiver Operating Characteristic (ROC) plots for Great Bustard habitat selection minimum adequate model to the data (a), and a validation plot (b) for survey data from 2004 not used in the analysis. 
Table 3. Predictors of number of male Great Bustards attending a display site (response variable, $n=160$ observations). Minimum adequate generalised linear model with Gaussian errors and controlling spatial autocorrelation with autologistic term.

\begin{tabular}{lllc}
\hline Retained Variables & Beta & SE & $t$ \\
\hline (Intercept) & 2.53 & 0.10 & $24.05^{* * *}$ \\
Autologistic term & 0.02 & 0.02 & 0.85 \\
No. of females & 0.19 & 0.03 & $6.77^{* * *}$ \\
MAM deviance & & 92.90 \\
\hline Removed Variables & Order of removal & $\Delta$ Deviance $^{\dagger}$ \\
\hline Dirt road density (m/km2) & 4 & 0.54 \\
Julian Day & 3 & 0.25 \\
Distance to road (m) & 2 & 0.12 \\
No. of females Julian Day & 1 & 0.01 \\
Maximal model deviance & & 91.98 \\
\hline
\end{tabular}

${ }^{\dagger}$ The change in deviance caused by the removal of the variable from the preceding model. Significances indicated as: $P<0.05^{*} ; P<0.01^{* *} ; P<0.001^{* * *}$.

of additive aggregation for determining attendance at sites. We found that male Great Bustards avoid human disturbance, and that variation in the number of males attending a display site was strongly correlated with the number of females. These results have implications for bustard conservation.

Great Bustards have a lek breeding system and consequently spatial autocorrelation and lek inertia (extreme site fidelity) are potential problems when studying habitat selection (Augustin et al. 1996, Lane et al. 2001, Osborne et al. 2001). Incorporation of spatial weighting allowed us to control for autocorrelation. The term was positive, indicating attraction between the locations of display sites which were likely to be within the 1,00o m lag distance of each other. Conversely, there was no spatial autocorrelation in the number of males attending display sites. This suggests that individuals were not simply congregating on traditional sites or close to them, but that numbers were dynamic across the large lekking areas. Therefore, lek inertia was unlikely to affect our interpretation of the attendance (Lane et al. 2001, Gray et al. 2007).

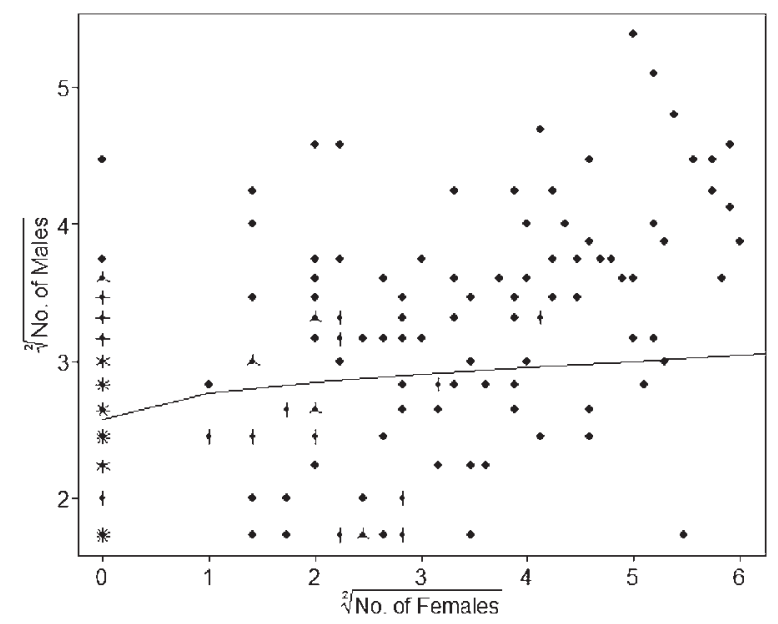

Figure 3. The number of male Great Bustards in relation to the number of females, and the predicting model (continuous line). Petals on the datum indicate sample sizes. 
Great Bustards chose displays sites farther from roads than expected by chance indicating avoidance of disturbance. This agrees with our a priori expectation as the negative impact of roads and the direct effect of anthropogenic activities have been seen in other populations (Lane et al. 2001, Suarez-Seoane et al. 2002, Sastre et al. 2009). The bustard family (Otididae) seems to have a predisposed vulnerability to disturbance, probably due to their predominantly terrestrial life history and ground nesting (Garcia et al. 2007, Gray et al. 2007, Dutta et al. 2011). Non-lethal anthropogenic disturbance caused by roads is a growing concern for conservationists as they can cause anti-predator behaviours such as fleeing, and may carry fitness costs (Miller et al. 1998, Goss-Custard et al. 2006, Cresswell 2008). Further, excessive disturbance may even lead to complete avoidance of otherwise suitable areas and ultimately altering space use and available habitat (Morales et al. 2006, Garcia et al. 2007, Speziale et al. 2008). This can be particularly acute for species with complex breeding systems or species that congregate to breed (Carney and Sydeman 1999, Manor and Saltz 2003). Human disturbance is an important consideration when managing or planning conservation for a species.

The number of males was strongly correlated with the number of female Great Bustards and not with disturbance. Positive correlation of males and females on display sites has been found in other lekking species, such as, the Ruff Philomachus pugnax, Black Grouse Tetrao tetrix and Sage Grouse Centrocercus urophasianus (Bradbury et al. 1989, Alatalo et al. 1991, Höglund et al. 1993). Three hypotheses have been advanced to explain the behaviour that leads to these aggregations. Firstly, the hotspot hypothesis suggests that males will congregate on areas where there are highest concentrations of females or overlapping female home ranges (Bradbury et al. 1986). Secondly, the hotshot hypothesis suggests dominant males will attract sub-dominant males which aim to parasitise successful males (Beehler and Foster 1988). Thirdly, female preference for larger aggregations of males may provide greater opportunities for comparison. Proving causality and exclusivity of these hypotheses has been problematic as cause and effect cannot be separated (Höglund and Alatalo 1995). However, behaviours that lead to aggregation are unlikely to be mutually exclusive and will likely operate with feedbacks. For example, overlapping female home ranges may initiate a display area which is visited by dominant males, thereby attracting subdominant males. Then females from other areas may also visit the larger congregation of males. Nevertheless, there is evidence that the probability of finding either sex is increased with the presence of the other.

Behaviours that lead to aggregation through influencing habitat choice can have important implications for population dynamics and species management. For example, conspecific attraction positively influences juvenile dispersal and in turn spatial metapopulation dynamics of Great Bustards (Alonso et al. 2004, Martin et al. 2008). Similar patterns are found across a broad range of animal taxa, including lizards, birds and mammals (Stamps 1988, Hoeck 1989, Weddell 1991, Gautier et al. 2006). The influence on population dynamics can lead to aggregation of territories, empty suitable habitat and increased extinction risk of patches (Ward and Schlossberg 2004).

Beyond considerations of habitat management, conspecific attraction could be used to actively manipulate spatial distribution for conservation purposes (Ahlering et al. 2010). Experimental studies have shown that site selection can be influenced using decoys and calls to simulate conspecific presence (Doligez et al. 2002, Ahlering and Faaborg 2006, Parker et al. 2007, Kappes et al. 2011). For instance, Jiguet and Bretagnolle (2006) demonstrated that Little Bustard Tetrax tetrax lek location, the number of individuals attending it and the composition of individuals, could be manipulated with the use of decoy conspecifics. Furthermore, decoys have been successfully used to aid recolonisation of empty habitats for colonial seabirds (Parker et al. 2007; but see Oro et al. 2011). Smith and Peacock (1990) highlighted the importance of considering conspecific attraction in reintroductions because the probability of utilising unoccupied suitable habitat is low, leading to a small number of occupied patches. Although we are not aware of formal testing, Great Bustards have been known to respond to decoys during hunting (Sowerby 1914), and although at an early stage, there has been promising use of decoys to influence the display sites of males in the UK Great Bustard reintroduction trial (pers. obs.). 
We found no effect of human disturbance on the number of male Great Bustards. We suggest two explanations for this. Firstly, the sites where Great Bustards occur were already high quality or at least minimally suitable for occupancy. It is likely that when a minimum threshold of tolerance is reached, decreasing disturbance has no bearing on the perceived quality of the habitat. Because the number of Great Bustards was not explained by heterogeneity in disturbance, abundance may be a misleading metric for habitat quality in Great Bustards or other social species (Vanhorne 1983, Stamps 1988, Skagen and Adams 2011). Strong conspecific attraction suggests that Great Bustards are vulnerable to an "ecological trap", whereby individuals remain faithful to a sub-optimal site and dispersing individuals select a site based on their presence (Székely 1992, Schlaepfer et al. 2002, Patten and Kelly 2010). Secondly, our proxies of human disturbance may not have captured the correct biological component. We cannot fully discount this argument, although note that human disturbance was important in influencing the probability of occupancy.

\section{Conclusions}

Here we found that human disturbance influences the spatial distribution of display sites although the abundance of males at a display site was best predicted by the number of conspecific females. Social cues are undervalued in conservation biology, and are not typically incorporated into habitat selection models (Fletcher and Sieving 2010). For the Great Bustard, which is experiencing habitat loss throughout its range and increasing fragmentation, the restoration of unoccupied habitats may prove futile, if the probability of colonisation is low. Ongoing and proposed reintroductions of the Great Bustard could potentially use conspecific attraction to manipulate habitat choice and to open up new habitats. Our study therefore adds to the growing evidence supporting the role of conspecific attraction in habitat choice and highlights its significance in conservation.

\section{Supplementary Material}

The supplementary materials for this article can be found at journals.cambridge.org/bci

\section{Acknowledgements}

We thank Hortobágy National Park authorities for providing sightings and grazing data and GIS layers for the national park. Thanks to P. Long for assistance with remote sensing image processing. Funding for the research was provided by the University of Bath. We would also like to thank the two anonymous reviewers and the editor for their feedback.

\section{References}

Ahlering, M. A. and Faaborg, J. (2006) Avian habitat management meets conspecific attraction: If you build it, will they come? Auk 123: 301-312.

Ahlering, M. A., Arlt, D., Betts, M. G., Fletcher, R. J., Nocera, J. J. and Ward, M. P. (2010) Research needs and recommendations for the use of conspecific-attraction methods in the conservation of migratory songbirds. Condor 112: 252-264.

Alatalo, R. V., Hoglund, J. and Lundberg, A. (1991) Lekking in the Black Grouse - a test of male viability. Nature 352: 155-156.
Alonso, J. C., Martin, C. A., Alonso, J. A., Palacin, C., Magana, M. and Lane, S. J. (2004) Distribution dynamics of a Great Bustard metapopulation throughout a decade: influence of conspecific attraction and recruitment. Biodivers. Conserv. 13: 1659-1674.

Augustin, N. H., Mugglestone, M. A. and Buckland, S. T. (1996) An autologistic model for the spatial distribution of wildlife. J. Appl. Ecol. 33: 339-347.

Beehler, B. M. and Foster, M. S. (1988) Hotshots, hotspots, and female preference in the organization of lek mating systems. Am. Nat. 131: 203-219. 
Beyer, H. L. (2004) Hawth's analysis tools for ArcGIS. Available at http://www.spatialecology.com/htools.

Bolker, B. M., Brooks, M. E., Clark, C. J., Geange, S. W., Poulsen, J. R., Stevens, M. H. H., and White, J. S. S. (2008) Generalized linear mixed models: a practical guide for ecology and evolution. Trends Ecol. Evol. 24:127-135.

Bradbury, J., Gibson, R. and Tsai, I. M. (1986) Hotspots and the dispersion of leks. Anim. Behav. 34: 1694-1709.

Bradbury, J. W., Gibson, R. M., McCarthy, C. E. and Vehrencamp, S. L. (1989) Dispersion of displaying male Sage Grouse. 2. The role of female dispersion. Behav. Ecol. Sociobiol. 24: 15-24.

Burnham, K. and Anderson, D. (2002) Model selection and multi-model inference. New York: Springer.

Burnside, R. J., Carter, I., Dawes, A., Waters, D., Lock, L., Goriup, P. and Székely, T. (2012) The UK Great Bustard Otis tarda reintroduction trial: a 5 year progress report. Oryx 46: 112-121.

Carney, K. M. and Sydeman, W. J. (1999) A review of human disturbance effects on nesting colonial waterbirds. Waterbirds 22: 68-79.

Crawley, M. J. (2007) The R book. UK: Wiley Publishing.

Cresswell, W. (2008) Non-lethal effects of predation in birds. Ibis 150: 3-17.

Crist, E. P. and Cicone, R. C. (1984) A physicallybased transformation of thematic mapper data- the TM tasseled cap. IEEE Trans. Geosci. Remote Sensing 22: 256-263.

Doligez, B., Danchin, E. and Clobert, J. (2002) Public information and breeding habitat selection in a wild bird population. Science 297: 1168-1170.

Dutta, S., Rahmani, A. R. and Jhala, Y. V. (2011) Running out of time? The Great Indian Bustard Ardeotis nigriceps-status, viability, and conservation strategies. Eur. J. Wildl. Res. 57: 615-625.

Eastman, J. R. (2003) Idrisi Kilimanjaro. (Guide to GIS and image processing.). Worcester: Clark Labs.

Ecsedi, Z., ed. (2004) A Hortobágy Madárvilága. Hortobágy Természetvédelmi Egyesület, Winter Fair.Szeged, Hungary: Balmazújváros.
Fletcher, R. J., Jr. (2007) Species interactions and population density mediate the use of social cues for habitat selection. J. Anim. Ecol. 76: 598-606.

Fletcher, R. J. and Sieving, K. E. (2010) Socialinformation use in heterogeneous landscapes: a prospectus. Condor 112: 225-234.

Freckleton, R. P. (2002) On the misuse of residuals in ecology: regression of residuals vs. multiple regression. J. Anim. Ecol. 71: 542-545.

Frid, A. and Dill, L. (2002) Human-caused disturbance stimuli as a form of predation risk. Conserv. Ecol. 6: 16 .

Garcia, J., Suarez-Seoane, S., Miquelez, D., Osborne, P. E. and Zumalacarregui, C. (2007) Spatial analysis of habitat quality in a fragmented population of Little Bustard (Tetrax tetrax): implications for conservation. Biol. Conserv. 137: 45-56.

Gautier, P., Olgun, K., Uzum, N. and Miaud, C. (2006) Gregarious behaviour in a salamander: attraction to conspecific chemical cues in burrow choice. Behav. Ecol. Sociobiol. 59: 836-841.

Gill, J. A., Norris, K. and Sutherland, W. J. (2001) The effects of disturbance on habitat use by Black-tailed Godwits Limosa limosa. J. Appl. Ecol. 38: 846-856.

Goss-Custard, J. D., Triplet, P., Sueur, F. and West, A. D. (2006) Critical thresholds of disturbance by people and raptors in foraging wading birds. Biol. Conserv. 127: 88-97.

Gray, T. N. E., Chamnan, H., Borey, R., Collar, N. J. and Dolman, P. M. (2007) Habitat preferences of a globally threatened bustard provide support for community-based conservation in Cambodia. Biol. Conserv. 138 : 341-350.

Hoeck, H. N. (1989) Demography and competition in hyrax. A 17 years study. Oecologia 79: 353-360.

Höglund, J. and Alatalo, R. V. (1995) Leks. Princeton: Princeton University Press.

Höglund, J., Montgomerie, R. and Widemo, F. (1993) Costs and consequences of variation in the size of Ruff leks. Behav. Ecol. Sociobiol. 32: 31-39.

Huang, C., Wylie, B., Yang, L., Homer, C. and Zylstra, G. (1998) Derivation of a tasseled cap transformation based on Landsat 7 
at-satellite reflectance. Sioux Falls: Raytheon ITSS USGS EROS Data Center. [http:// landcover.usgs.gov/pdf/tasseled.pdf accessed, 12/06/10].

Jiguet, F. and Bretagnolle, V. (2006) Manipulating lek size and composition using decoys: an experimental investigation of lek evolution models. Am. Nat. 168: 758-768.

Johnson, M. D. (2007) Measuring habitat quality: a review. Condor 109: 489-504.

Jones, J. (2001) Habitat selection studies in avian ecology: a critical review. Auk 118: 557-562.

Kappes, P. J., Mcchesney, G. J., Parker, M. W., Carter, H. R., Kress, S. W. and Golightly, R. T. (2011) Use of time-activity budgets to measure early progress of a social attraction restoration project. Biol. Conserv. 144: 620-626.

Kauth, R. J. and Thomas, G. S. (1976) The tasseled cap - a graphic description of the spectral temporal development of agricultural crops as seen by Landsat. Pp. 41-51 in Proceedings of the symposium on machine processing of remotely sensed data. West Lafayette: Perdue University.

Lane, S. J., Alonso, J. C. and Martin, C. A. (2001) Habitat preferences of Great Bustard Otis tarda flocks in the arable steppes of central Spain: are potentially suitable areas unoccupied? J. Appl. Ecol. 38: 193-203.

Manor, R. and Saltz, D. (2003) Impact of human nuisance disturbance on vigilance and group size of a social ungulate. Ecol. Appl. 13: 1830-1834.

Martin, C. A., Alonso, J. C., Alonso, J. A., Palacin, C., Magana, M. and Martin, B. (2008) Natal dispersal in Great Bustards: the effect of sex, local population size and spatial isolation. J. Anim. Ecol. 77: 326-334.

Miller, S. G., Knight, R. L. and Clinton, K. M. (1998) Influence of recreational trails on breeding bird communities. Ecol. Appl. 8: 162-169.

Morales, M. B. and Martin, C. (2003) Otis tarda, Great Bustard. Birds of the Western Palearctic Update: 4: 217-232.

Morales, M. B., Jiguet, F. and Arroyo, B. (2001) Exploded leks: what bustards can teach us? Ardeola 48: 85-98.

Morales, M. B., Suarez, F. and De La Morena, E. L. G. (2006) Response of steppe birds to various levels of farming intensity and of modification of the agricultural landscape: a comparative analysis of their effects on population density and habitat selection in the Little and Great Bustards (Tetrax tetrax and Otis tarda). Revue d' Ecologie-La Terre Et La Vie 61: 261-270.

Morris, D. W. (2003) Toward an ecological synthesis: a case for habitat selection. Oecologia 136: 1-13.

Muller, K. L., Stamps, J. A., Krishnan, V. V. and Willits, N. H. (1997) The effects of conspecific attraction and habitat quality on habitat selection in territorial birds (Troglodytes aedon). Am. Nat. 150: 650-661.

Mundry, R. (2011) Issues in information theorybased statistical inference - a commentary from a frequentist's perspective. Behav. Ecol. Sociobiol. 65: 57-68.

Oro, D., Martinez-Abrain, A., Villuendas, E., Sarzo, B., Minguez, E., Carda, J. and Genovart, M. (2011) Lessons from a failed translocation program with a seabird species: Determinants of success and conservation value. Biol. Conserv. 144: 851-858.

Osborne, P. E., Alonso, J. C. and Bryant, R. G. (2001) Modelling landscape-scale habitat use using GIS and remote sensing: a case study with Great Bustards. J. Appl. Ecol. 38 : 458-471.

Palacin, C. and Alonso, J. C. (2008) An updated estimate of the world status and population trends of the Great Bustard Otis tarda. Ardeola 55: 13-25.

Parker, M. W., Kress, S. W., Golightly, R. T., Carter, H. R., Parsons, E. B., Schubel, S. E., Boyce, J. A., Mcchesney, G. J. and Wisely, S. M. (2007) Assessment of social attraction techniques used to restore a Common Murre colony in central California. Waterbirds 30 : 17-28.

Patten, M. A. and Kelly, J. F. (2010) Habitat selection and the perceptual trap. Ecol. Appl. 20: 2148-2156.

R Development Core Team (2011). R: A language and environment for statistical computing. Vienna: R Foundation for Statistical Computing. [http://www.R-project.org, accessed 2 May 2011].

Root-Bernstein, M. and Ladle, R. J. (2010) Conservation by design. Conserv. Biol. 24: 1205-1211. 
Sastre, P., Ponce, C., Palacin, C., Martin, C. A. and Alonso, J. C. (2009) Disturbances to Great Bustards (Otis tarda) in central Spain: human activities, bird responses and management implications. Eur. J. Wildl. Res. 55:425-432.

Schlaepfer, M. A., Runge, M. C. and Sherman, P. W. (2002) Ecological and evolutionary traps. Trends Ecol. Evol. 17: 474-480.

Skagen, S. K. and Adams, A. A. Y. (2011) Potential misuse of avian density as a conservation metric. Conserv. Biol. 25: $48-55$.

Smith, A. T. and Peacock, M. M. (1990) Conspecific attraction and the determination of metapopulation colonization rates. Conserv. Biol. 4: 320-323.

Sowerby, A. D. C. (1914) Fur and feather in North China. Tientsin: Tientsin Press.

Speziale, K. L., Lambertucci, S. A. and Olsson, O. (2008) Disturbance from roads negatively affects Andean Condor habitat use. Biol. Conserv. 141: 1765-1772.
Stamps, J. A. (1988) Conspecific attraction and aggregation in territorial species. Am. Nat. 131: 329-347.

Suarez-Seoane, S., Osborne, P. E. and Alonso, J. C. (2002) Large-scale habitat selection by agricultural steppe birds in Spain: identifying species-habitat responses using generalized additive models. J. Appl. Ecol. 39: 755-771.

Székely, T. (1992) Reproduction of Kentish Plover Charadrius alexandrinus in grasslands and fish-ponds: the habitat malassessment hypothesis. Aquila 99: 59-68.

Vanhorne, B. (1983) Density as a misleading indicator of habitat quality. J. Wildl. Mgmt. 47: 893-901.

Ward, M. P. and Schlossberg, S. (2004) Conspecific attraction and the conservation of territorial songbirds. Conserv. Biol. 18: 519-525.

Weddell, B. J. (1991) Distribution and movements of Columbian Ground Squirrels (Spermophilus columbianus): are habitat patches like islands? J. Biogeogr 18: 385-394.

ROBERT J. BURNSIDE*, TAMÁS SZÉKELY

Biodiversity Lab, Department of Biology and Biochemistry, University of Bath, Claverton Down, Bath BA2 7AY, UK.

ZSOLT VÉGVÁRI

Department of Conservation Zoology, Hortobágy National Park Directorate, University of Debrecen Sumen u. 2. Debrecen H-4024, Hungary.

RICHARD JAMES

Department of Physics, University of Bath, Claverton Down, Bath BA2 7AY, UK.

SANDOR KONYHÁS, GÁBOR KOVÁCS

Hortobágy National Park Directorate, Sumen u. 2. Debrecen H-4024, Hungary.

*Author for correspondence; e-mail: robertjohnburnside@hotmail.com

Received o3 February 2012; revision accepted o3 August 2012;

Published online 28 March 2013 